\title{
Visualization of Pathway Usage in an Extended Carbohydrate Conversion Network Reveals the Impact of Solvent Enabled Proton Transfer
}

\author{
Jensen, Pernille Rose; Knudsen, Rikke K.; Meier, Sebastian
}

Published in:

ACS Sustainable Chemistry and Engineering

Link to article, DOI:

10.1021/acssuschemeng.0c04073

Publication date:

2020

Document Version

Peer reviewed version

Link back to DTU Orbit

Citation (APA):

Jensen, P. R., Knudsen, R. K., \& Meier, S. (2020). Visualization of Pathway Usage in an Extended

Carbohydrate Conversion Network Reveals the Impact of Solvent Enabled Proton Transfer. ACS Sustainable Chemistry and Engineering, 8(32), 12270-12276. https://doi.org/10.1021/acssuschemeng.0c04073

\section{General rights}

Copyright and moral rights for the publications made accessible in the public portal are retained by the authors and/or other copyright owners and it is a condition of accessing publications that users recognise and abide by the legal requirements associated with these rights.

- Users may download and print one copy of any publication from the public portal for the purpose of private study or research.

- You may not further distribute the material or use it for any profit-making activity or commercial gain

- You may freely distribute the URL identifying the publication in the public portal 


\section{Impact of Solvent Enabled Proton Transfer}

5 Pernille R. Jensen - Technical University of Denmark, Department of Health Technology,

$7 \quad{ }^{\S}$ Rikke K. Knudsen - Technical University of Denmark, Department of Chemistry, Kemitorvet

9 'Sebastian Meier - Technical University of Denmark, Department of Chemistry, Kemitorvet 
13 ABSTRACT: Bio-sourced molecules should increasingly contribute to meeting societal demands

14 for energy and chemicals, while reducing net carbon dioxide release and the dependence on fossil

15 resources. Especially oxygenated chemicals can be derived from carbohydrates, and the

16 conversion of carbohydrates in protic and non-protic solvents has attracted considerable interest.

17 Here we probe chemocatalytic carbohydrate conversion in a time-resolved manner using

18 quantitative in situ NMR spectroscopy. A core reaction network in the carbohydrate conversion

19 by $\operatorname{Sn}(\mathrm{IV})$ in non-protic solvents is followed by identifying and quantitatively tracking ten

20 chemicals with more than 70 atomic sites. The in situ analysis yields nine rate constants and shows

21 that (co)solvents with labile protons strongly affect tautomerization kinetics and product

22 distributions at an upstream branch point of the reaction network. Solvent enabled tautomerization

23 and the ensuing accumulation of reactive 1,2-dicarbonyl compounds can thus be key factors

24 influencing reaction kinetics and atom economy in carbohydrate conversion.

25 KEYWORDS: Biomass conversion, Catalysis, Carbohydrate utilization, Humin formation,

26 Kinetic Model, NMR spectroscopy, Reaction Network 


\section{INTRODUCTION}

30 There is a broad consensus that a future sustainable society will depend on the production of 31 materials and fuels from abundant renewable substrates rather than fossil resources. ${ }^{1}$

32 Lignocellulosic biomass, and especially carbohydrates, play a leading role as prospective natural

33 resources for oxygenated compounds with high chemical functionality. Current progress in

34 endeavors towards viable carbohydrate-based processes is arguably limited by restricted insight

35 into the multiple carbohydrate conversion pathways towards different (by)products. Carbohydrate

36 conversion pathways often encompass acid- or base-catalysed dehydration, isomerization or (retro-

37 )aldol reactions. These pathways can encompass acyclic and cyclic forms, ${ }^{2-4}$ and free aldehyde

38 groups whose high reactivity is difficult to control. ${ }^{5-6}$ Hence, various acyclic and cyclic pathways

39 may coexist, and the factors influencing substrate influx into the different pathways remain

40 difficult to understand and control. Most notoriously, the relative importance of various plausible

41 pathways towards furanic compounds has remained controversial for many decades, possibly due

42 to the involvement of different pathways towards the product. ${ }^{4,7-9}$

43 In the conversion of carbohydrates, different solvents and solvent systems have attracted

44 interest. The solvents should ideally solubilize the carbohydrate at sufficiently high concentration

45 and stabilize intermediates against aggregation reactions. Reactions in water often lead to the

46 formation of undesired side products. ${ }^{10}$ Alcoholic solvents have a tendency to mask aldehyde

47 groups as unreactive acetals and to covalently add to double bond functionalities ${ }^{11}$ formed by

48 dehydration reactions. ${ }^{12-13}$ Aprotic polar solvents and ionic liquids have therefore attracted

49 particular interest, although product purification can be hampered in such solvents. ${ }^{3,14-16}$ 


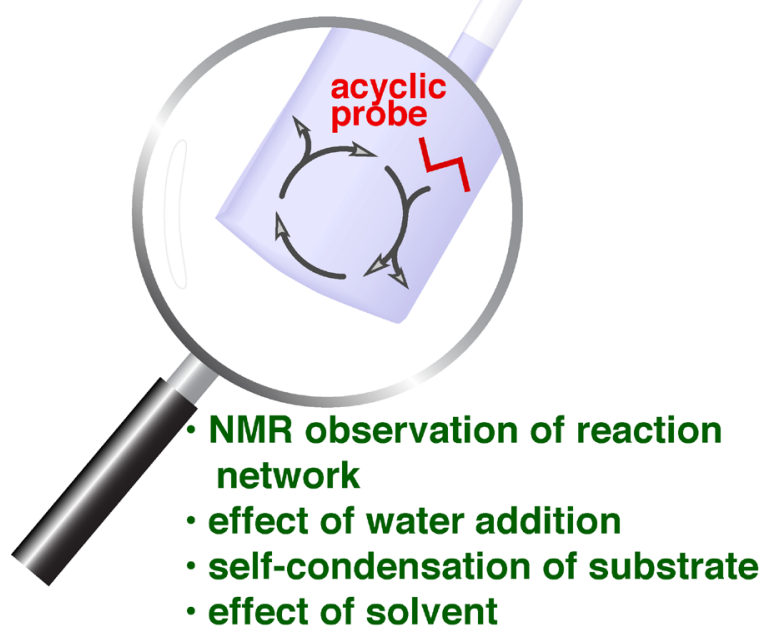

52 Figure 1. Schematic overview of the questions addressed herein using erythrulose as an acyclic 53 probe molecule to track usage and control of different reaction pathways that are accessible to 54 acyclic carbohydrate substrates.

56 The experimental observation of carbohydrate conversion networks and their response to 57 changes in reaction conditions has remained a challenge (Figure 1). High-field NMR spectroscopy 58 emerges as a suitable means to obtaining definitive answers on the molecular forms and their 59 conversion kinetics in complex reactions mixtures, without the need for sample workup. ${ }^{2,11-13,17-}$

$60{ }^{21}$ Here we hypothesized that in situ spectroscopy can shed light on the chemical pathways that are 61 accessible to acyclic carbohydrate forms in aprotic polar solvents under mild reaction conditions.

62 The majority of reactions that have been described for acyclic carbohydrate conversion entail 63 intramolecular redox and dehydration reactions at C1-C4., 13, 22-26 Hence, these reactions can be 64 probed using the $\mathrm{C} 4$ substrate erythrulose as the substrate. A special emphasis is placed herein on 65 reactions that leave the carbon backbone intact or lead to self-condensation. 
Recently, the conversion of abundant C6 sugars by Lewis acids ${ }^{16}$ in acyclic pathways was

70 described. ${ }^{3,20}$ We undertook to enquire the Lewis acid catalyzed conversion of carbohydrates in

71 polar environments, using erythrulose as a molecular probe for the reaction network that is

72 accessible with the cheap and widely available Lewis acids $\mathrm{SnCl}_{4}$ in DMSO.${ }^{16}$ Previously elusive

73 mechanistic details concern (1) branch points in the reaction network, (2) substrates and kinetics

74 for self-condensation in humin formation, (3) the kinetic impact of cyclic intermediates (such as

75 3-deoxyglycosones) and (4) the molecular effect of water addition and choice of solvent on the

76 reaction network (Figure 1).

77 Rationale for using an acyclic probe in aprotic solvent. The use of erythrulose in aprotic solvent

78 promises to efficiently channel substrate into the reaction network for the conversion of acyclic

79 carbohydrates. Opposite to acyclic erythrulose, the C6 analogue fructose has an open chain

80 population of only approximately $2.4 \%$ in DMSO near room temperature, ${ }^{17}$ thus decreasing

81 substrate population interactions with the Lewis acidic catalyst (Figure 2). As a consequence,

82 erythrulose was found to be converted substantially faster than fructose, as shown by reaction

83 tracking with a time series of ${ }^{13} \mathrm{C}$ NMR spectra (Figure 2a). In this sense, fructose and other longer

84 ketoses mask the reactive carbonyl group through intramolecular hemiketal or hemiacetal

85 formation to cyclic forms. Similarly, conversion of carbohydrates in alcoholic solvents leads to

86 the formation of hemiketals/hemiacetals or ketals/acetals that mask the carbonyl groups as solvent

87 adducts. Use of erythrulose in aprotic solvents thus stands as a particularly strong means of

88 populating reaction pathways that involve the coordination of free carbonyl groups to Lewis acidic

89 catalysts.

90 

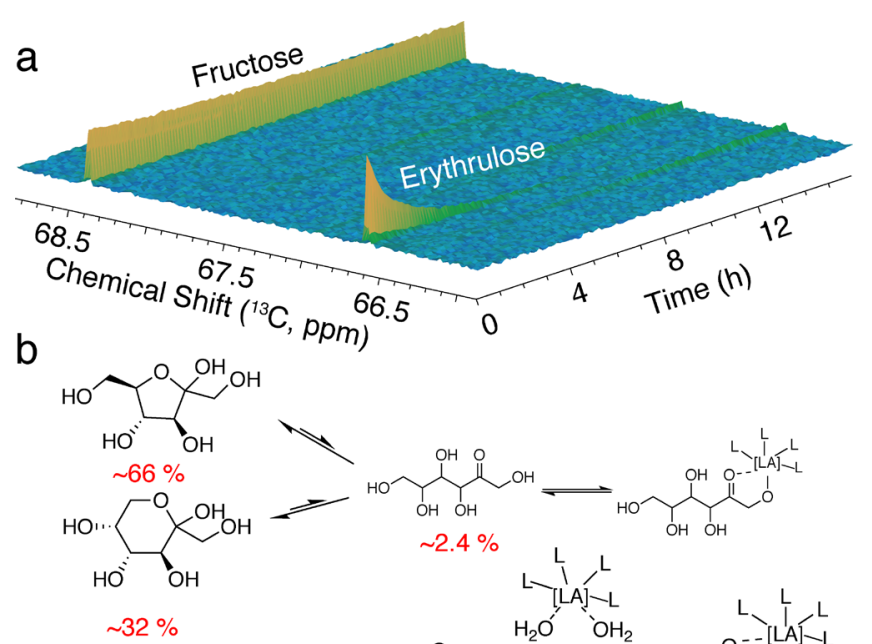

92 Figure 2. (a) Conversion of a mixture of fructose and erythrulose shows the higher reactivity of

93 erythrulose due to the higher acyclic population. (b) Schematic overview of higher acyclic fraction

94 leading to higher populations of complexes with the schematically depicted Lewis acid (here $\mathrm{Sn}^{\mathrm{IV}}$,

95 Ligands are indicated as $\mathrm{L}$ due to the possibility of partial $\mathrm{SnCl}_{4}$ hydrolysis). Reaction conditions:

96 L-erythrulose $(27 \mathrm{mg})$, D-fructose $(40 \mathrm{mg})$ and $\mathrm{SnCl}_{4} \cdot 5 \mathrm{H}_{2} \mathrm{O}(10 \mathrm{mg})$ in $\mathrm{d}_{6}-\mathrm{DMSO}(550 \mu \mathrm{L})$ at 313

$97 \mathrm{~K}$.

Tracking of an extended reaction network. Subsequently, the conversion of erythrulose by

$99 \mathrm{SnCl}_{4}$ in polar aprotic solvent (DMSO) was followed using quantitative in situ NMR at high

100 magnetic field (800 MHz spectrometer equipped with a TCI cryoprobe to maximize the signal-to

101 noise ratio in the resultant spectra). In addition to the more trivial isomerization products erythrose

102 and threose, nine dehydration products could be tracked in a time resolved manner (Figure 3 and

103 Figure 4). Kinetic profiles of the resultant reaction progress curves supported the full assignment

104 of the chemical compounds shown in Scheme 1. The assignments were completed by the use of

105 homo- and heteronuclear assignment spectra, specifically ${ }^{1} \mathrm{H}-{ }^{1} \mathrm{H}$ TOCSY, ${ }^{1} \mathrm{H}-{ }^{1} \mathrm{H}$ COSY, ${ }^{1} \mathrm{H}-{ }^{13} \mathrm{C}$

106 HSQC and ${ }^{1} \mathrm{H}-{ }^{13} \mathrm{C}$ HMBC spectra, which also yielded ${ }^{1} \mathrm{H}$ NMR shifts for all non-labile protons. 
108 reaction pathways as shown in Scheme 1, while Figure S2 depicts the corresponding complexation

109 of the metal center. Aldotetrose signals decayed with a kinetics akin to erythrulose and were treated

110 as part of the carbohydrate substrate pool (Figure S3). The first detected dehydrated intermediate

111 is the enol 2, which corresponds to the enol form of a 3-deoxythreosone (4-hydroxy-2-oxobutanal,

112 the cyclic keto tautomer is entry 5). The keto tautomer $\mathbf{5}$ forms subsequently, in parallel to vinyl 113 glyoxal (3), which readily rehydrates at the $\mathrm{C} 1$ position and is detected as the hydrate. Vinyl

114 glyoxal (3) is an unstable intermediate that reacts to vinyl glycolate (4) through a 1,2-hydride shift

115 of the C1-hydrated form. In contrast, the 3-deoxythreosone intermediate 5 proves more resilient to 116 hydride shifts, forming a fairly stable product at $313 \mathrm{~K}$ that only slowly converts to the 117 hydroxybutyrolactone (6), and the corresponding acyclic esters (9).

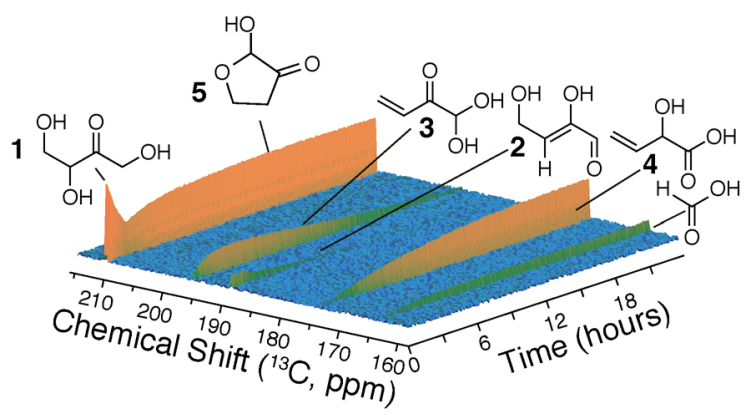

120 Figure 3. Conversion of erythrulose and some of the major carbonyl- and carboxyl-containing 121 reaction products that were formed. Reaction conditions: L-erythrulose (27 $\mathrm{mg})$, D-fructose (40 $122 \mathrm{mg})$ and $\mathrm{SnCl}_{4} \cdot 5 \mathrm{H}_{2} \mathrm{O}(10 \mathrm{mg})$ in $\mathrm{d}_{6}-\mathrm{DMSO}(550 \mu \mathrm{L})$ at $313 \mathrm{~K}$. 
124 Scheme 1. Conversion of erythrulose through a reaction network entailing two branch points.

125 Chemical shifts were assigned using reaction-progress curves and two-dimensional assignment 126 spectra.

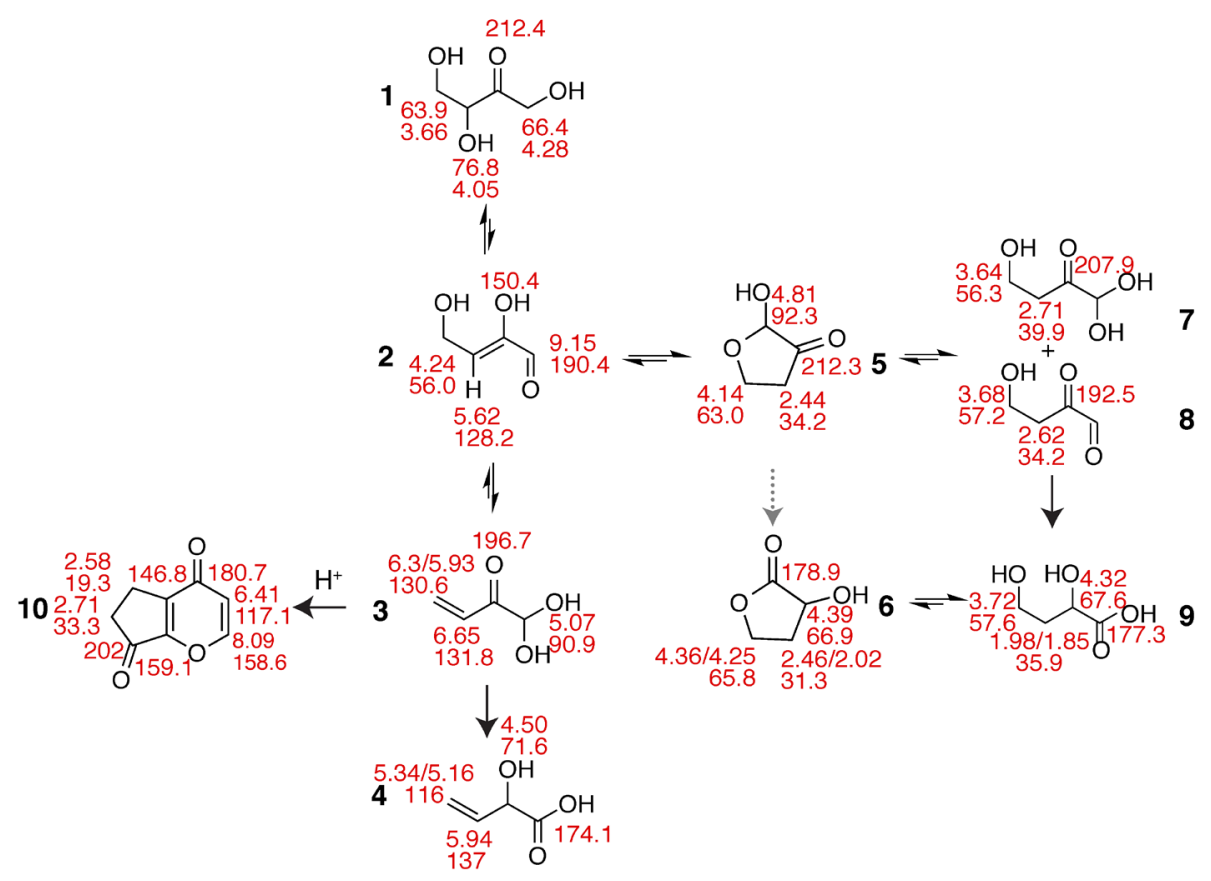

130 accumulation of the free corresponding 1,2-dicarbonyl compounds, indicating a kinetic impact of

131 hemiacetal and hydrate forms that are more stable than their 1,2-dicarbonyl counterparts. The

132 predominance of the cyclic structure 5 was evident from characteristic chemical shifts, especially

133 for ${ }^{1} \mathrm{H}$ and ${ }^{13} \mathrm{C}$ at the $\mathrm{C} 4-\mathrm{H} 4$ position, and from long-range connections in the ${ }^{1} \mathrm{H}-{ }^{13} \mathrm{C}$ HMBC

134 experiment (Figure S4). The observation is consistent with previous observations that $85 \%$ of 135 compound $\mathbf{5}$ exist as a cyclic form even in purely aqueous solution. ${ }^{27}$ Only upon addition of water 136 to the reaction mixture could acyclic forms 7 and $\mathbf{8}$ of the 3 -deoxythreosone be observed. In the 137 conversion of $\mathbf{5}$ to $\mathbf{6}$, kinetic experiments at varying temperatures indicated that the acyclic form 9 138 was formed prior to $\mathbf{6}$, followed by equilibration of 9 and $\mathbf{6}$ (Figure S5). This observation is 
139 consistent with the interpretation that the cyclic form $\mathbf{5}$ accumulates as the least reactive form of

140 3-deoxythreosone.

\section{$141 \quad$ Kinetic model consistent with the reaction network}

142 The reaction pathway of Scheme 1 was incorporated into a simple kinetic model and the 143 experimental reaction progress data for the main intermediates was fitted to the kinetic model.

144 Fitting quantitative experimental data for seven molecular species (Figure 4) supported the simple 145 reaction model of Scheme 1 and Figure 5. Previous observations had shown that the conversion of 146 1,2-dicarbonyl compounds (such as 3 and 5) to $\alpha$-hydroxy acids was irreversible. ${ }^{11,} 28$ 147 Spectroscopic data likewise indicated that the conversion of 3 was quantitative (Figure 4) and 148 would have a small reversible reaction rate constant. The parallel formation of

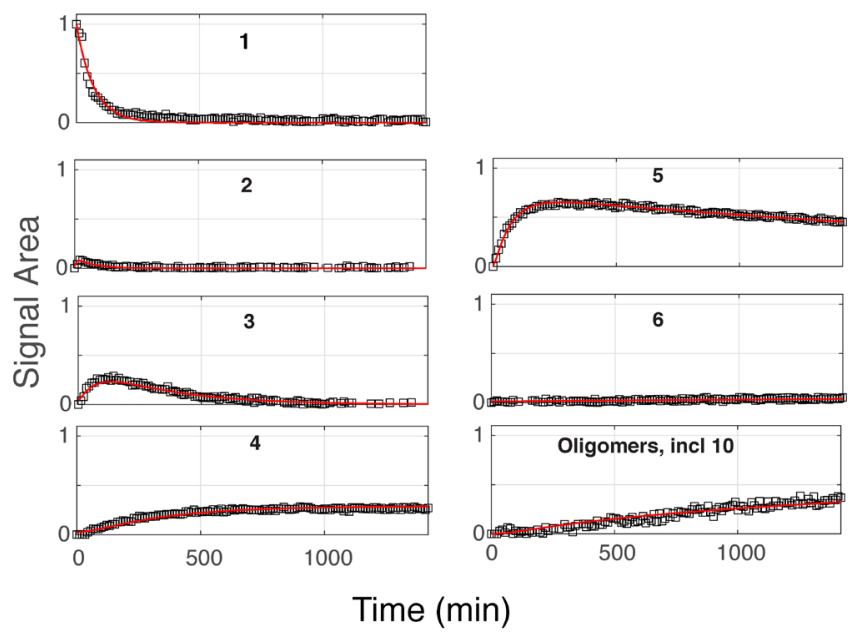

150 Figure 4. Integrals of carbon signals in compounds 1-6 alongside residual other species (especially

151 oligomers and polymers), for the conversion of erythrulose under the conditions of Figure 3 . The 152 experimental data shown as black squares were in agreement with a kinetic model of Figure 5. Red 153 lines depict from kinetic modelling calculations. 


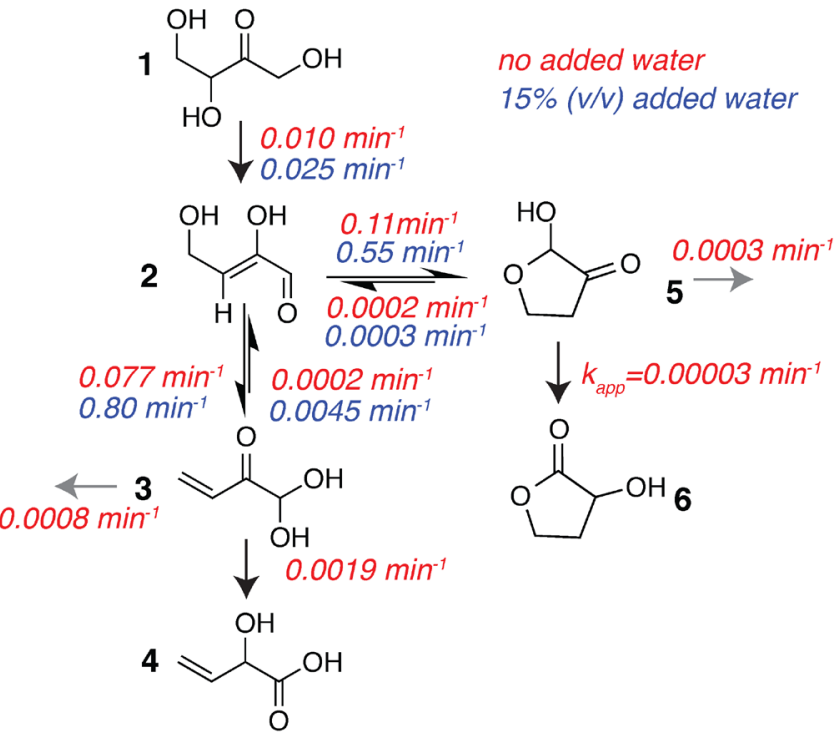

155 Figure 5. Kinetic model that is consistent with kinetic reaction progress data for the erythrulose 156 conversion at $313 \mathrm{~K}$. Reactions were treated as irreversible steps in order to avoid overfitting of 157 the data set. The data indicated slow oligomerization of the alpha carbonyl aldehydes $\mathbf{3}$ and $\mathbf{5}$ (red 158 arrows).

159 compounds $\mathbf{3}$ and $\mathbf{5}$ from $\mathbf{2}$ indicates the formation in largely irreversible competitive steps in the 160 absence of added water (red values in Figure 4 designate rate constants in the absence of water). 161 The weakly accumulating open enol form 2 was elusive to previous observation. Allowing for 162 reversibility of the first step did not significantly improve the fitting and did not affect the obtained 163 constants.

164 These rate constants show erythrulose conversion to compound 2 with a rate constant that 165 is approximately eightfold lower than the conversion of $\mathbf{2}$ to $\mathbf{3}$, and one order of magnitude lower 166 than the enol-to-ketone conversion of $\mathbf{2}$ to $\mathbf{5}$ (red values in Figure 5). The conversion of 167 intermediates $\mathbf{3}$ and $\mathbf{5}$ through hydride shifts is orders of magnitude slower than the formation of $168 \mathbf{3}$ and $\mathbf{5}$ from $\mathbf{2}$ (Figure 5). Kinetic fits indicated that the alpha-carbonyl aldehyde forms $\mathbf{3}$ and $\mathbf{5}$ 169 are precursors for oligomers and polymers (humins), consistent with recent suggestions that alpha- 
170 carbonyl aldehydes undergo aldol condensation to form humins. ${ }^{6}$ This conversion was faster from

171 vinyl glyoxal (3) than from the circular hemiacetal 5 (Figure 5). The instability of vinyl glyoxal

172 was further witnessed by the observation of formic acid forming in parallel to vinyl glycolate (4)

173 upon accumulation of the 1,2-dicarbonyl species 3 (Figure S6). Rather notably, liberation of formic

174 acid from a $\beta-\gamma$ unsaturated $\alpha$-hydroxy-carbonyl intermediate is analogous to the proposed

175 mechanism in the conversion of HMF to levulinic acid via $\beta-\gamma$ unsaturated $\alpha$-hydroxy-carbonyl

176 intermediate. ${ }^{29}$

177 The slower conversion of compound $\mathbf{5}$ as compared to compound $\mathbf{3}$ is a hallmark in the

178 conversion of the 1,2-dicarbonyl compounds $\mathbf{3}$ and $\mathbf{5}$ to the respective $\alpha$-hydroxy acids. The

179 observation of a fairly rapid formation, but slow turnover of the 3-deoxythreosone intermediate

180 stipulated the search for conditions that disfavour the conversion of compound $\mathbf{5}$ in favour of 181 enolization and conversion through the acyclic pathway to compound 4 that has been considered 182 the more useful chemical due to its vinyl functionality.

184 Water-enabled tautomerization affects the branch point between cyclic and acyclic routes.

185 The competing conversions of the previously elusive enol intermediate $\mathbf{2}$ involve tautomerization 186 steps. Water is known to have a noteworthy catalytic impact on Tautomerization reactions, because 187 it can mediate necessary intramolecular proton transfer. ${ }^{30-31}$ Added water should additionally 188 facilitate populating the hydrated vinyl glyoxal 3. Hence, water was added to the reaction mixture 189 at fractions of $7.5 \%(\mathrm{v} / \mathrm{v})$ or $15 \%(\mathrm{v} / \mathrm{v})$ and the effects on reaction progress were monitored by in 190 situ NMR spectroscopy (Figure 6). The resultant experiments indeed showed that the population 191 of $\mathbf{5}$ could be diminished by the addition water, while influx of intermediate $\mathbf{2}$ into the hydrated 192 acyclic form $\mathbf{3}$ was favored. Accumulation of intermediate $\mathbf{3}$ and 


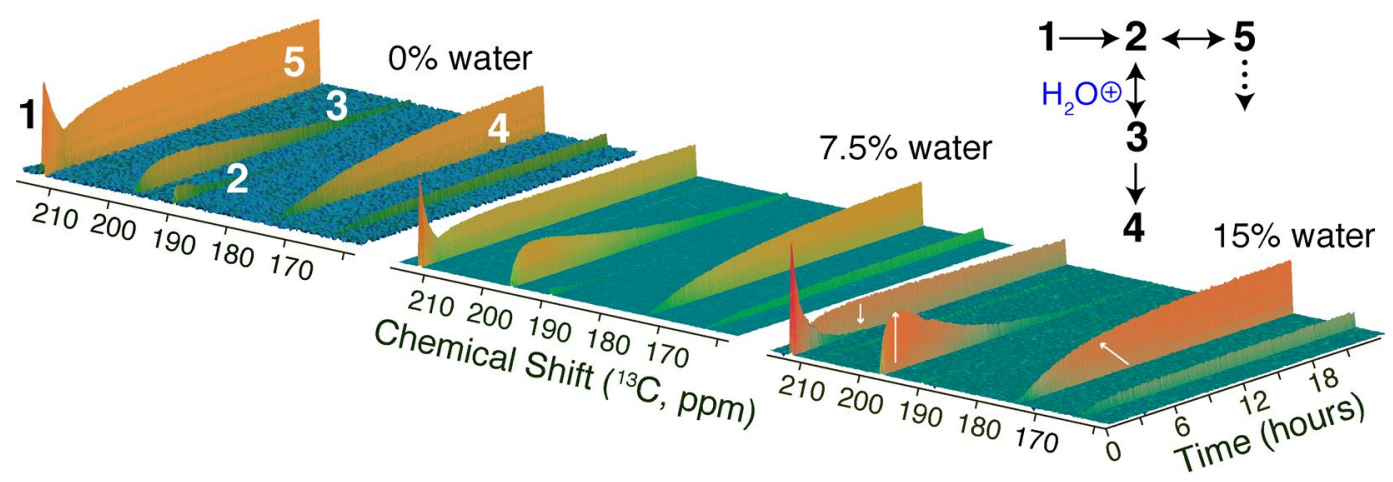

194 Figure 6. Conversion of erythrulose to central intermediates and products in the presence of 195 varying amounts of water. Reaction conditions: L-erythrulose (27 mg), D-fructose (40 mg) and $196 \mathrm{SnCl}_{4} \cdot 5 \mathrm{H}_{2} \mathrm{O}(10 \mathrm{mg})$ in $\mathrm{d}_{6}-\mathrm{DMSO} / \mathrm{D}_{2} \mathrm{O}$ of the indicated ratio (v/v added water, total $\left.550 \mu \mathrm{L}\right)$ at $197313 \mathrm{~K}$.

198 product formation of $\mathbf{4}$ were accelerated as a consequence. In contrast, accumulation of molecule $199 \mathbf{2}$ declined upon addition of water. Only in the presence of water did the kinetic profiles of $\mathbf{3}$ and 2005 deviate from kinetically controlled competitive formation, consistent with water catalysis 201 facilitating reversible tautomerization.

202 Overall, the observations indicated that water addition noticeably favored the conversion of 2 to $203 \mathbf{3}$ over its cyclization to $\mathbf{5}$. These observations provide a mechanistic basis for previous coincidental 204 observations, which indicated that pathways to C6-analogues of 4 can be favored over pathways 205 to cyclic compounds by the addition of water. ${ }^{3}$ As anticipated, water catalysis had a strong effect 206 on the kinetics of tautomerization reactions, where the rate constant for the conversion of $\mathbf{2}$ to $\mathbf{3}$ 207 was more strongly enhanced than the rate constant rate constant for conversion of $\mathbf{2}$ to $\mathbf{5}$ (see blue 208 values in Figure 5 above for a comparison of the rate constants). 
212 Water effect on self-condensation. Further studies of the water effect were conducted to

213 monitor the composition of post reaction material obtained in the presence of increasing water

214 content. These experiments validated a decrease of compound 5 , but increase of compound 4 at

215 low water content. In addition, a new compound emerged at increased water content, especially

216 for higher temperatures (Figure S6). The additional compound yielded eight correlating ${ }^{13} \mathrm{C}$ signals

217 of identical area. This C8 compound with characteristic chemical shifts was subsequently

218 identified as erythropyrone $\mathbf{1 0}$, formed from the condensation of two $\mathrm{C} 4$ compounds. A plausible

219 mechanism for the condensation is schematically depicted in Scheme $2 .{ }^{32}$ The accumulation of

220 erythropyrone is in agreement with the accumulation of vinyl glyoxal. The role of Brønsted acidity

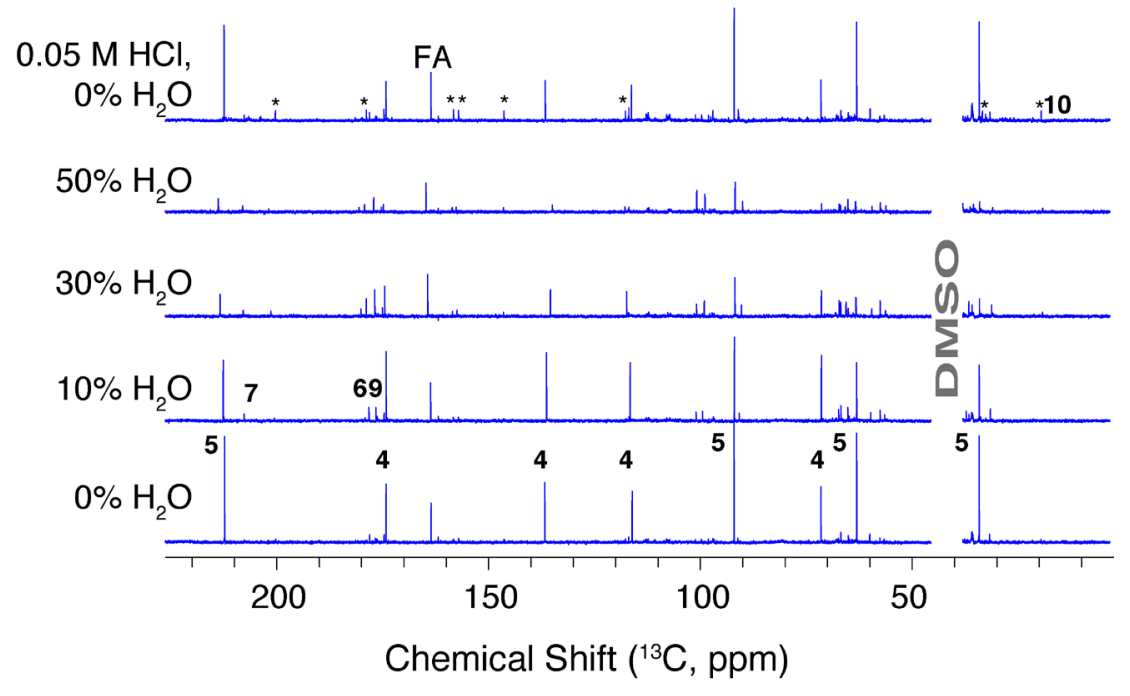

Figure 7. ${ }^{13} \mathrm{C}$ NMR spectra of post reaction material for reactions with varying water content and

223 added Brønsted acid. Reaction conditions: L-erythrulose $(40 \mathrm{mg})$ and $\mathrm{SnCl}_{4} \cdot 5 \mathrm{H}_{2} \mathrm{O}(10 \mathrm{mg})$ in $\mathrm{d}_{6}-$

$224 \mathrm{DMSO} / \mathrm{D}_{2} \mathrm{O}(\mathrm{v} / \mathrm{v}$ as indicated, $550 \mu \mathrm{L})$ at $313 \mathrm{~K}$ for 24 hours. A reference reaction was conducted

225 in $\mathrm{d}_{6}$-DMSO $(550 \mu \mathrm{L})$ containing $50 \mathrm{mM} \mathrm{HCl}(\mathrm{aq})$. Asterisks indicate erythropyrone (10) signals. 
228 Scheme 2. Plausible reaction pathway for the conversion of erythrulose to a self-condensed C8-

229 product, erythropyrone, by reaction with vinyl glyoxal intermediate. ${ }^{32} 33$

230

231

232

233

234

235

236

237

238

239

240

241

242

243

244

245 thus finally compared to reaction progress in aprotic polar DMF and in the protic polar methanol

246 and ethanol solvents.

in the formation of erythropyrone was validated by repeating the experiment in the presence of $50 \mathrm{mM} \mathrm{HCl}$ in the reaction mixture of $\mathrm{SnCl}_{4}$ in $\mathrm{DMSO}$, again causing the accumulation of erythropyrone 10 (Figure 7). In addition, accumulation of the reactive vinyl glyoxal intermediate (3) was observed in the presence of added water (Figure 6). Discoloration and the formation of insoluble material in the post-reaction mixture were aggravated by increasing temperature and water content, both of which favour the conversion of 2 to vinyl glyoxal (3) (Figure S11 and S12).

Distinct solvent influence of protic versus aprotic media. Considering the apparent role of free carbonyl groups in coordinating the Lewis acidic catalyst, and the role of labile protons in catalyzing tautomerization reactions, polar protic solvents and polar aprotic solvents were expected to show significantly different reaction progress curves. Polar protic solvents such as short chain alcohols have a tendency to add to aldehyde and olefinic groups and should interfere with some of the reactions of Scheme 1. In order to evaluate, if reaction progress in polar protic and polar aprotic solvents falls into two distinct categories, the reaction progress in DMSO was and ethanol solvents.

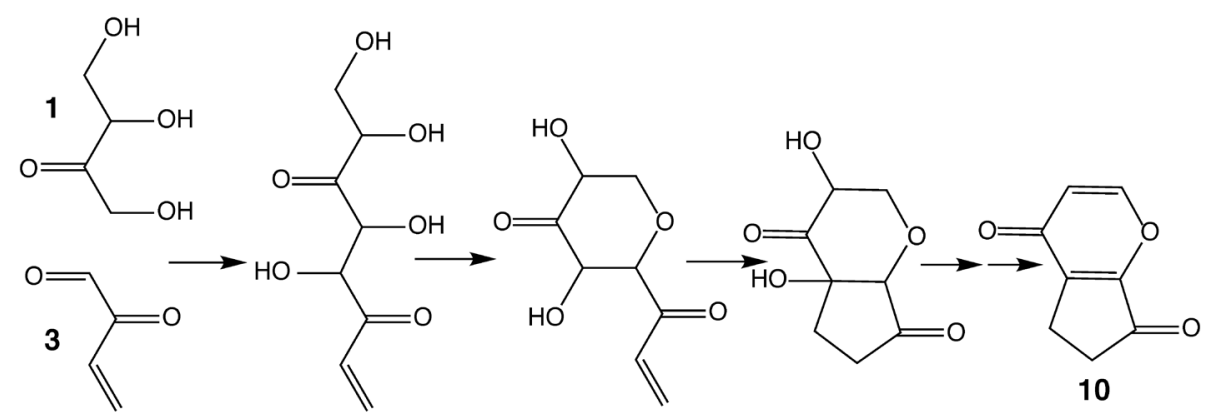


248 from the reaction profiles in methanol and ethanol (Figure 8 and Figure S15). Rather notably, the

249 conversion of erythrulose substrate was faster in protic solvents facilitating tautomerization

250 (Figure S15). In the alcoholic solvents, none of the intermediates $\mathbf{2}, \mathbf{3}$ or $\mathbf{5}$ accumulated to

251 significant amounts. In contrast, the alcohol rapidly added to the vinyl glyoxal intermediate

252 forming a C4 ether variant of 3-deoxythreosone, predominantly found as a hemiacetal with the
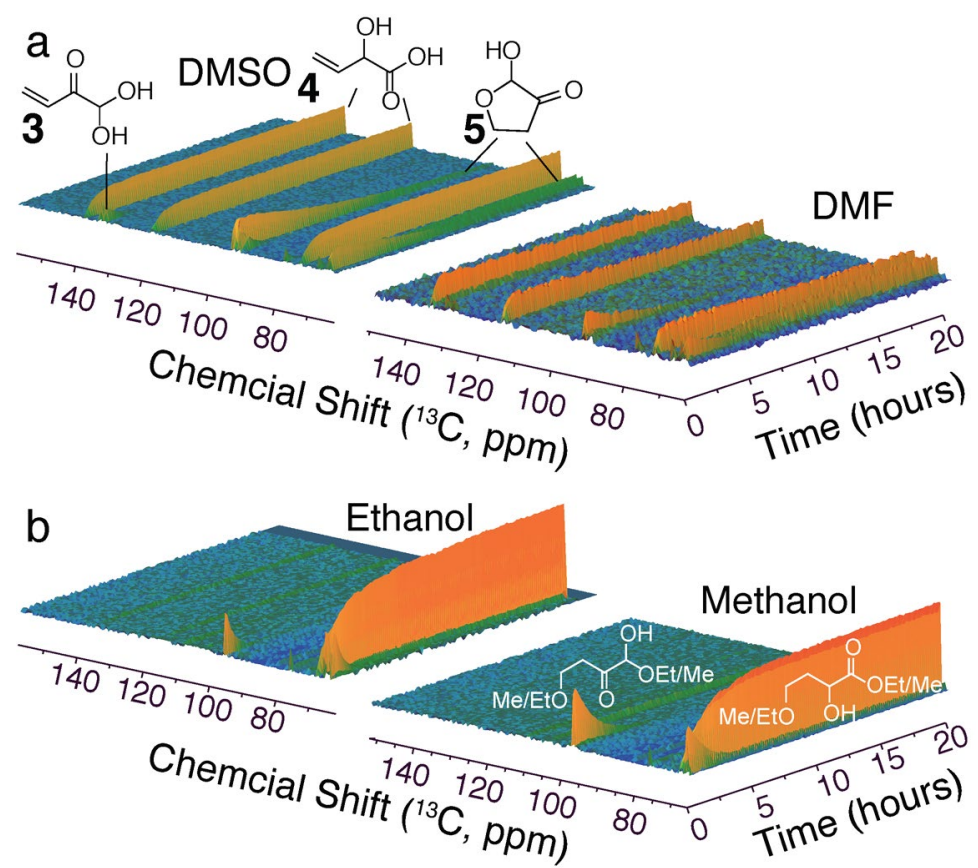

255 Figure 8. Reaction progress in various aprotic (a) and protic (b) solvents. Reaction conditions: L256 erythrulose $(40 \mathrm{mg})$ and $\mathrm{SnCl}_{4} \cdot 5 \mathrm{H}_{2} \mathrm{O}(10 \mathrm{mg})$ in $550 \mu \mathrm{L} \mathrm{d}_{6}$-DMSO, protonated DMF containing $2575 \% \mathrm{~d}_{6}$-DMSO, methanol or ethanol containing 5\% (v/v) $\mathrm{d}_{4}-\mathrm{methanol}_{\text {at }} 333 \mathrm{~K}$.

258 alcohol at the $\mathrm{C} 1$ position (Figure 8b). The changes in pathway usage are thus consistent with 259 the effect of water addition on reaction kinetics in DMSO: protic polar solvents favor the pathway 260 through the transient vinyl glyoxal intermediate, while disfavoring the pathway through 3- 
261 deoxythreosone as compared to aprotic polar solvents. As a result, the product composition in

262 alcoholic solvents is simpler than the product composition in the polar aprotic solvents, which

263 enable two pathways of similar propensity for $\mathrm{C} 4$ substrates.

265 CONCLUSION

266 An extensive reaction network was observable in a time-resolved manner for the Lewis acid 267 catalysed conversion of a model carbohydrate in DMSO. Rate constants for the central reactions 268 could be determined, including those of reactions that led to the formation of insoluble products.

269 The product distribution, including the formation of (usually undesired) humins, was affected by

270 the addition of water. Kinetic curves indicated that two competing products, 3-deoxythreosone and

271 vinyl glyoxal, formed in competing reactions under kinetic control in the absence of added water.

272 Addition of water and higher temperature changed the reaction control at the branch point, thus

273 also favouring self-condensation and humin formation. Reaction kinetics of upstream

274 tautomerization steps and ensuing accumulation of intermediates and products can thus be strongly

275 affected by the presence of solvent containing labile protons. The observations further show that

276 the hydration and intramolecular ring formation of free carbonyl groups affect pathway kinetics.

277 In situ reaction tracking and structural identifications reported herein may facilitate the

278 implementation of conditions that disfavour undesired pathways in carbohydrate upgrading. 279

281 EXPERIMENTAL SECTION

282 Materials. D-(-)-fructose ( $\geq 99 \%)$, L-(+)-erythrulose (85\%), tin(IV) chloride pentahydrate 283 (98\%), tin(II) trifluoromethanesulfonate, aluminium(III) chloride hexahydrate (\%), titanium(IV) 
284 chloride (99.9\%), $d_{6}$-dimethylsulfoxide (\%), and $\mathrm{D}_{2} \mathrm{O}(\%)$ were purchased from Sigma-Aldrich 285 (Andover, MA, USA). $\mathrm{HCl}\left(4 \mathrm{M}\right.$ in $\left.\mathrm{H}_{2} \mathrm{O}\right)$ was purchased from Fluka and used as a stock solution 286 in probing the effect of Brønsted acidity. Different metal salts were used in an initial screening 287 approach (Figure S1) to show that Tin(IV) catalysed reactions described herein equivalently occur 288 under $\mathrm{Al}(\mathrm{III})$ catalysis and to some extent with Tin(II) catalysis.

290 Reaction procedures. Carbohydrates were dissolved in $d_{6}$-DMSO at the indicated 291 concentrations in $1.5 \mathrm{ml}$ Eppendorf safelock tubes. Deuterated water $\left(\mathrm{D}_{2} \mathrm{O}\right)$ was added to a final 292 volume ratio (v/v) as indicated. Tin(IV) chloride or other metal salt catalysts were added from a 293 stock solution, usually to a final carbohydrate:catalyst molar ratio of $\sim 12: 1$ (40 mg erythrulose and $29410 \mathrm{mg} \mathrm{SnCl} 4 \cdot 5 \mathrm{H}_{2} \mathrm{O}$, unless stated otherwise). Subsequently, reaction mixtures were (a) either 295 transferred to $5 \mathrm{~mm}$ NMR sample tubes for in situ reaction tracking or (b) the Eppendorf tubes 296 containing $550 \mu \mathrm{l}$ of reaction mixture were incubated on a Hettich Thermo Shaker MHR13 297 equipped with a thermoblock at $298 \mathrm{~K}, 313 \mathrm{~K}, 323 \mathrm{~K}, 333 \mathrm{~K}$ or $363 \mathrm{~K}$ and the indicated times for 298 compositional analysis and chemical shift assignments of post reaction material.

300 NMR spectroscopy. NMR spectra were acquired with a Bruker Avance II $800 \mathrm{MHz}$ NMR 301 spectrometer equipped with an $18.7 \mathrm{~T}$ magnet (Oxford, United Kingdom) and a TCI z-gradient 302 cryoprobe (Bruker, Karlsruhe, Germany). For the assignment of chemicals in post reaction 303 material, samples were transferred to $5 \mathrm{~mm}$ NMR tubes for NMR analysis. A suite of 2D NMR 304 assignment spectra was acquired, including TOCSY with a $10 \mathrm{kHz}$ spin lock field that was applied 305 for $60 \mathrm{~ms}(1024 \times 128$ complex data points with $128 \mathrm{~ms}$ and $16 \mathrm{~ms}$ acquisition times), a sensitivity 306 enhanced ${ }^{1} \mathrm{H}-{ }^{13} \mathrm{C}$ HSQC $(1024 \times 128$ complex points, sampling $107 \mathrm{~ms}$ and $3.2 \mathrm{~ms}$ acquisition 
times), ${ }^{1} \mathrm{H}-{ }^{13} \mathrm{C}$ HMBC $(1024 \times 256$ complex data points, sampling 128 and $5.7 \mathrm{~ms}$ acquisition times $)$

308 and a ${ }^{1} \mathrm{H}^{-13} \mathrm{C}$ HSQC TOCSY with adiabatic decoupling $(2048 \times 128$ complex points with $160 \mathrm{~ms}$

309 and 3.9 ms acquisition times). ${ }^{13} \mathrm{C}$ NMR spectra were acquired by sampling the ${ }^{13} \mathrm{C}$ FID during an

310 acquisition time of 1.36 seconds with $64 \mathrm{k}$ complex data points with an inter-scan relaxation delay

311 of 10 seconds between 256 accumulations.

312 In situ experiments were performed as time series of ${ }^{13} \mathrm{C} 1 \mathrm{D}$ NMR spectra by immediately

313 transferring reaction mixtures to $5 \mathrm{~mm}$ NMR tubes and equilibrating the NMR tubes to the desired

314 temperature in the spectrometer. Time series of ${ }^{13} \mathrm{C}$ spectra were recorded in a pseudo-2D fashion

315 to facilitate the integration of signal areas in the Dynamics Module of Bruker Topspin 4.0.6. The

$316{ }^{13} \mathrm{C}$ FID was sampled by acquiring 32k complex data points during an acquisition time of 0.68

317 seconds. An inter-scan relaxation delay of 10 seconds $\left(\sim 5 \times \mathrm{T}_{1}\right)$ per time point was used for reaction

318 tracking. All protonated (non-quaternary) ${ }^{13} \mathrm{C}$ sites of each analyte molecule were used for

319 integration. The identical kinetic profile of four carbon sites (of comparable signal area) in each of

320 the C4-molecular species 1-9 aided and validated the assignment of the molecular species as

321 depicted in Scheme 1 below.

322 All NMR spectra were recorded, processed with ample zero filling in all spectral

323 dimensions, and analysed with Bruker Topspin 4.0.6 software (Fällanden, Switzerland).

325 Data Analysis. A kinetic model was devised of sequential reactions for the signal areas of core

326 compounds $\mathbf{1}-\mathbf{6}$ as well as signal area that is lost in undetectable polymeric forms. Nonlinear least-

327 squares fitting of the time-dependent signal areas was conducted in MATLAB using the fmincon

328 function for the following differential equations: 
$330 \quad \frac{d[\mathbf{1}](t)}{d t}=-k_{1} \times[\mathbf{1}](t)$

$$
\frac{d[2](t)}{d t}=k_{1} \times[\mathbf{1}](t)-k_{2} \times[2](t)-k_{5} \times[2](t)+k_{-2} \times[3](t)+k_{-5} \times[5](t)
$$

$$
\frac{d[3](t)}{d t}=k_{2} \times[2](t)-k_{3} \times[3](t)-k_{4} \times[3](t)-k_{-2} \times[3](t)
$$

$333 \quad \frac{d[4](t)}{d t}=k_{3} \times[3](t)$

$$
\frac{d[5](t)}{d t}=k_{5} \times[2](t)-k_{6} \times[5](t)-k_{7} \times[5](t)-k_{-5} \times[5](t)
$$

$335 \quad \frac{d[6](t)}{d t}=k_{6} \times[5](t)$

$$
\frac{d[\text { oligomers }](t)}{d t}=k_{4} \times[3](t)+k_{7} \times[5](t)
$$

338 Square brackets indicate the signal areas, while $k$ denotes first order rate constants. Satisfactory

339 fits were only obtained when invoking the loss of detected signal from the 1,2-dicarbonyl

340 compounds 3 and 5. Previous observations had shown that the conversion of 1,2-dicarbonyl

341 compounds (such as 3 and 5) to $\alpha$-hydroxy acids (such as 4) was irreversible, ${ }^{11,28}$ Spectroscopic

342 data likewise indicated that no NMR-detectable equilibrium between $\mathbf{3}$ and $\mathbf{4}$ was formed. Kinetic

343 data showed that reversibility of upstream tautomerization reaction plays an increasingly important

344 role in the presence of protic solvent.

347 Supporting Information. Supplementary figures include NMR spectra of product mixtures

348 derived upon catalyst screening; assignment spectra for the identification of 3-deoxythreosone

349 forms; time-resolved in situ NMR spectra for reaction tracking at varying water content and 
350 temperature; detailed depiction of kinetic fits in the absence and in the presence of water;

351 comparison of substrate conversion in various protic and aprotic solvents

352 AUTHOR INFORMATION

\section{Corresponding Author}

$354 *$ Sebastian Meier - Technical University of Denmark, Department of Chemistry, Kemitorvet

355 Building 207, 2800-Kgs. Lyngby, Denmark; e-mail semei@kemi.dtu.dk

\section{Author Contributions}

357 The manuscript was written through contributions of all authors. All images in Schemes and

358 Figures were created by the authors. All authors have given approval to the final version of the

359 manuscript.

360 Notes

361 The authors declare no competing financial interests.

362 ACKNOWLEDGMENTS

363 This work was funded by the Innovation Fund Denmark (case number 5150-00023B) and the

364 Danish National Research Foundation (DNRF124). 800 MHz NMR spectra were recorded on the 365 spectrometer of the NMR Center DTU supported by the Villum Foundation.

367 REFERENCES

368 (1) Centi, G.; Čejka, J., Needs and Gaps for Catalysis in Addressing Transitions in Chemistry 369 and Energy from a Sustainability Perspective. ChemSusChem 2019, 12 (3), 621-632. 370 https://doi.org/10.1002/cssc.201802637 
(2) Jensen, P. R.; Taarning, E.; Meier, S., Probing the Lewis Acid Catalyzed Acyclic Pathway

372 of Carbohydrate Conversion in Methanol by In Situ NMR. ChemCatChem 2019, 11 (20), $5077-$

373 5084. https://doi.org/10.1002/cctc.201901241

374 (3) Taarning, E.; Sádaba, I.; Jensen, P. R.; Meier, S., Discovery and Exploration of the 375 Efficient Acyclic Dehydration of Hexoses in DMSO/Water. ChemSusChem 2019, 12 (23), 5086376 5091. https://doi.org/10.1002/cssc.201902322

377 (4) Tolborg, S.; Meier, S.; Sádaba, I.; Elliot, S. G.; Kristensen, S. K.; Saravanamurugan, S.; 378 Riisager, A.; Fristrup, P.; Skrydstrup, T.; Taarning, E., Tin-containing silicates: Identification of a 379 glycolytic pathway via 3-deoxyglucosone. Green Chem. 2016, 18 (11), 3360-3369. 380 https://doi.org/10.1039/C5GC02840J

381 (5) Bender, T. A.; Dabrowski, J. A.; Gagné, M. R., Homogeneous catalysis for the production 382 of low-volume, high-value chemicals from biomass. Nat. Rev. Chem. 2018, 2 (5), 35-46. 383 https://doi.org/10.1038/s41570-018-0005-y

384 (6) Shi, N.; Liu, Q.; Ju, R.; He, X.; Zhang, Y.; Tang, S.; Ma, L., Condensation of $\alpha$-Carbonyl 385 Aldehydes Leads to the Formation of Solid Humins during the Hydrothermal Degradation of 386 Carbohydrates. ACS Omega 2019, 4 (4), 7330-7343. https://doi.org/10.1021/acsomega.9b00508

387 (7) Antal, M. J.; Mok, W. S. L.; Richards, G. N., Mechanism of formation of 5388 (hydroxymethyl)-2-furaldehyde from d-fructose and sucrose. Carbohydr. Res. 1990, 199 (1), 91389 109. https://doi.org/10.1016/0008-6215(90)84096-D

390 (8) van Putten, R.-J.; van der Waal, J. C.; de Jong, E.; Rasrendra, C. B.; Heeres, H. J.; de Vries, 391 J. G., Hydroxymethylfurfural, A Versatile Platform Chemical Made from Renewable Resources. 392 Chem. Rev. 2013, 113 (3), 1499-1597. https://doi.org/10.1021/cr300182k 
(9) Rasmussen, H.; Sørensen, H. R.; Meyer, A. S., Formation of degradation compounds from

394 lignocellulosic biomass in the biorefinery: sugar reaction mechanisms. Carbohydr. Res. 2014, 385, 45-57. https://doi.org/10.1016/j.carres.2013.08.029

(10) Qi, X.; Smith Jr, R. L.; Fang, Z., Production of Versatile Platform Chemical 5397 Hydroxymethylfurfural from Biomass in Ionic Liquids. In Production of Biofuels and Chemicals 398 with Ionic Liquids. Biofuels and Biorefineries; Fang Z., Smith, Jr. R., Qi X., Eds; Springer: 399 Dordrecht, 2014, Vol. 1, pp 223-254. https://dx.doi.org/10.1007/978-94-007-7711-8_9

400 (11) Tosi, I.; Riisager, A.; Taarning, E.; Jensen, P. R.; Meier, S., Kinetic analysis of hexose 401 conversion to methyl lactate by Sn-Beta: effects of substrate masking and of water. Catal. Sci. 402 Technol. 2018, 8 (8), 2137-2145. https://doi.org/10.1039/C8CY00335A

(12) Dusselier, M.; Van Wouwe, P.; de Clippel, F.; Dijkmans, J.; Gammon, D. W.; Sels, B. F.,

Mechanistic Insight into the Conversion of Tetrose Sugars to Novel $\alpha$-Hydroxy Acid Platform Molecules. ChemCatChem 2013, 5 (2), 569-575. https://doi.org/10.1002/cctc.201200476

(13) Dusselier, M.; Van Wouwe, P.; De Smet, S.; De Clercq, R.; Verbelen, L.; Van Puyvelde,

P.; Du Prez, F. E.; Sels, B. F., Toward Functional Polyester Building Blocks from Renewable 408 Glycolaldehyde with Sn Cascade Catalysis. ACS Catal. 2013, 3 (8), 1786-1800. https://doi.org/10.1021/cs400298n

410 (14) Rasrendra, C. B.; Soetedjo, J. N. M.; Makertihartha, I. G. B. N.; Adisasmito, S.; Heeres, 411 H. J., The Catalytic Conversion of d-Glucose to 5-Hydroxymethylfurfural in DMSO Using Metal 412 Salts. Top. Catal. 2012, 55 (7), 543-549. https://doi.org/10.1007/s11244-012-9826-y

413 (15) Qi, X.; Watanabe, M.; Aida, T. M.; Smith, J. R. L., Efficient process for conversion of 414 fructose to 5-hydroxymethylfurfural with ionic liquids. Green Chem. 2009, 11 (9), 1327-1331. 415 https://doi.org/10.1039/B905975J 
(16) Hu, S.; Zhang, Z.; Song, J.; Zhou, Y.; Han, B., Efficient conversion of glucose into 5-

417 hydroxymethylfurfural catalyzed by a common Lewis acid $\mathrm{SnCl}_{4}$ in an ionic liquid. Green Chem. 418 2009, 11 (11), 1746-1749. https://doi.org/10.1039/B914601F

419 (17) Akien, G. R.; Qi, L.; Horváth, I. T., Molecular mapping of the acid catalysed dehydration 420 of fructose. Chem. Comm. 2012, 48 (47), 5850-5852. https://doi.org/10.1039/C2CC31689G

421 (18) Amarasekara, A. S.; Williams, L. D.; Ebede, C. C., Mechanism of the dehydration of d422 fructose to 5-hydroxymethylfurfural in dimethyl sulfoxide at $150^{\circ} \mathrm{C}$ : an NMR study. Carbohydr. 423 Res. 2008, 343 (18), 3021-3024. https://doi.org/10.1016/j.carres.2008.09.008

424 (19) Meier, S., Kinetic variations in acid-catalyzed monosaccharide conversion. Catal. Comm. 425 2020, 135, 105894. https://doi.org/10.1016/j.catcom.2019.105894

426 (20) Meier, S., Mechanism and malleability of glucose dehydration to HMF: entry points and 427 water-induced diversions. Catal. Sci. Technol. 2020, 10, 1724-1730. 428 https://doi.org/10.1039/C9CY02567G

429 (21) Zhang, J.; Weitz, E., An in Situ NMR Study of the Mechanism for the Catalytic Conversion 430 of Fructose to 5-Hydroxymethylfurfural and then to Levulinic Acid Using 13C Labeled d431 Fructose. ACS Catal. 2012, 2 (6), 1211-1218. https://pubs.acs.org/doi/10.1021/cs300045r

432 (22) Roman-Leshkov, Y.; Moliner, M.; Labinger, J. A.; Davis, M. E., Mechanism of glucose 433 isomerization using a solid Lewis acid catalyst in water. Angew. Chem. 2010, 49 (47), 8954-7. 434 https://doi.org/10.1002/anie.201004689

435 (23) Holm, M. S.; Saravanamurugan, S.; Taarning, E., Conversion of Sugars to Lactic Acid 436 Derivatives Using Heterogeneous Zeotype Catalysts. Science 2010, 328 (5978), 602-605. 437 https://doi.org/10.1126/science.1183990 
(24) Holm, M. S.; Pagán-Torres, Y. J.; Saravanamurugan, S.; Riisager, A.; Dumesic, J. A.;

439 Taarning, E., Sn-Beta catalysed conversion of hemicellulosic sugars. Green Chem. 2012, 14 (3),

440 702-706. https://doi.org/10.1039/c2gc16202d

441 (25) Saravanamurugan, S.; Riisager, A.; Taarning, E.; Meier, S., Mechanism and 442 stereoselectivity of zeolite-catalysed sugar isomerisation in alcohols. Chem. Commun. 2016, 52 443 (86), 12773-12776. https://doi.org/10.1039/C6CC05592C

444 (26) De Clercq, R.; Dusselier, M.; Sels, B. F., Heterogeneous catalysis for bio-based polyester 445 monomers from cellulosic biomass: advances, challenges and prospects. Green Chem. 2017, 19 446 (21), 5012-5040. https://doi.org/10.1039/C7GC02040F

447 (27) Weenen, H.; van der Ven, J. G. M.; van der Linde, L. M.; van Duynhoven, J.; 448 Groenewegen, A., C4, C5, and C6 3-Deoxyglycosones: Structures and Reactivity. In The Maillard 449 Reaction in Foods and Medicine, O'Brien, J.; Nursten, H. E.; Crabbe, M. J. C.; Ames, J. M., Eds.; 450 Woodhead Publishing: Cambridge, 2005; pp 57-64. https://doi.org/10.1533/9781845698447.2.57 451 (28) Pighin, E. A.; Di Cosimo, J. I.; Díez, V. K., Kinetic and mechanistic study of triose sugar 452 conversion on Lewis and Brønsted acid solids. Mol. Catal. 2018, 458, 189-197. 453 https://doi.org/10.1016/j.mcat.2017.11.026

454 (29) Horvat, J.; Klaić, B.; Metelko, B.; Šunjić, V., Mechanism of levulinic acid formation. 455 Tetrahedron Lett. 1985, 26 (17), 2111-2114. https://doi.org/10.1016/S0040-4039(00)94793-2

456 (30) Gorb, L.; Leszczynski, J., Intramolecular Proton Transfer in Mono- and Dihydrated 457 Tautomers of Guanine: An ab Initio Post Hartree-Fock Study. J. Am. Chem. Soc. 1998, 120, 5024 458 - 5032. https://doi.org/10.1021/ja972017w 
(31) Alagona, G.; Ghio, C.; Nagy, P. I., The catalytic effect of water on the keto-enol 460 tautomerism. Pyruvate and acetylacetone: a computational challenge. Phys. Chem. Chem. Phys. 461 2010, 12 (35), 10173-10188. https://doi.org/10.1039/C003999C

462 (32) Feather, M. S.; Harris, J. F., Dehydration Reactions of Carbohydrates, in Advances in 463 Carbohydrate Chemistry and Biochemistry, Tipson, R. S.; Horton, D., Eds. Academic Press: 1973;

464 Vol. 28, pp 161-224. https://doi.org/10.1016/S0065-2318(08)60383-2

465 (33) Shi, N.; Liu, Q.; Cen, H.; Ju, R.; He, X.; Ma, L., Formation of humins during degradation 466 of carbohydrates and furfural derivatives in various solvents. Biomass Convers. Bior. 2020, 10, 467 277-287. https://doi.org/10.1007/s13399-019-00414-4

468 (34) Enslow, K. R.; Bell, A. T., $\mathrm{SnCl}_{4}$-catalyzed isomerization/dehydration of xylose and 469 glucose to furanics in water. Catal. Sci. Technol. 2015, 5 (5), 2839-2847. 470 https://doi.org/10.1039/C5CY00077G

471 (35) Catala, F.; Defaye, J.; Laszlo, P.; Lederer, E., Action Des Acides Mineraux Sur Le D472 Erythrose. Isolement Et Structure De Lerythropyrone. Bull. Soc. Chim. Fr. 1964, (12), 3182-3187.

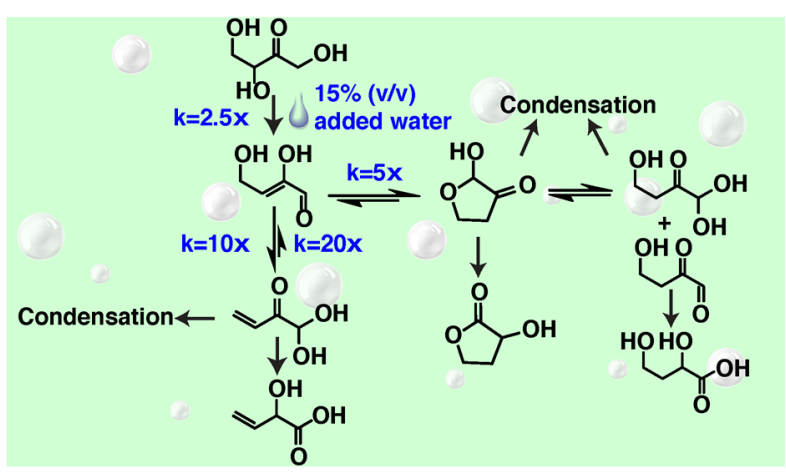


480 A reaction network for carbohydrate valorization was observed, revealing the impact of solvent 481 protons on the desired process, and on aggregation and degradation reactions. 